\title{
EDUCAÇÃO HUMANIZADORA E O USO DAS TECNOLOGIAS
}

\author{
Anderson Luiz Tedesco* \\ Roque Strieder ${ }^{*}$ \\ Tiago Eurico de Lacerda ${ }^{* * *}$
}

RESUMO: Objetiva-se com esse estudo refletir a respeito da construção de práticas didáticas com uso das TICS no processo de ensino aprendizagem em uma perspectiva de educação humanizadora. Trata-se de uma investigação, cujo delineamento metodológico, constitui-se em um estudo bibliográfico. Concluiu-se com base na literatura investiga a necessidade de criar políticas públicas que assegurem espaços de formação continuada aos educadores e gestores das escolas, sem dúvida o resultado dessa reflexão é a construção viável e possível de processos educacionais humanizantes e de práticas docentes que incluam o uso de tecnologias no formar seres humanos críticos e sensibilizados com os diferentes modos de viveres.

PALAVRAS-CHAVE: Educação; Formação Continuada; Humanização; Tecnologia.

\section{Introdução}

Muito se tem discutido, recentemente, a respeito das novas tecnologias da informação e comunicação (NTIC) e quando esse tema é discutido precisa envolver o meio escolar, a fonte do conhecimento e os professores devem ser os primeiros a se desafiarem a interagir com os processos de inovação tecnológica disponíveis para se ter uma aula desejante,

\footnotetext{
* Doutor em Filosofia Pela Pontifícia Universidade Católica do Paraná (Puc-PR). Professor da Universidade Comunitária de Chapecó (Unochapecó). Temáticas de Estudo: Ética e a Educação. Formação Humana e Tecnologia.

${ }^{* *}$ Doutor em Educação pela Universidade Metodista de Piracicaba (Unimep-SP). Professor do Programa de Mestrado em Educação da Universidade do Oeste de Santa Catarina (Unoesc). Temáticas de estudo: Educação Humana. Ética e Educação. Grupo de Pesquisa: Formação Docente e Práticas de Ensino.

*** Doutor em Filosofia Pela Pontifícia Universidade Católica do Paraná (Puc-PR). Professor da Universidade Tecnológica do Paraná (UFTPR).
} 
construtiva e que resulte e aprendizagens significantes. Nesta perspectiva temos diversos paradigmas e desafios na construção de práticas didáticas que incluam as TICs, em seus contextos educativos. Não se pode mais postergar o novo na escola, é o momento da mudança de uma educação bancaria, para uma formação humana e, por conseguinte uma educação humanizante nos processos formativos.

Deste modo a inquietude dessa reflexão se constitui no pensar os o uso e a aplicabilidade do uso das tecnologias em sala de aula nas séries iniciais, como fazer do ambiente escolar um local desejante. As novas práticas pedagógicas do aprender e do ensinar relacionam-se com tecnologias que potencializam o ensino, com elas criam-se novas possibilidades de aprendizagem, pois entende-se que cada educando aprende de uma maneira diferente e as tecnologias auxiliam na abertura de caminhos diversos na educação para melhorar os laços de convivência dos aprendentes, precisamente porque a educação deve estar cada vez mais ligada a espaços formativos do pensar a complexidade do ser humano e do aprender novas formas de viveres.

Para realização desse estudo sobre o uso das tecnologias aliados ao ensino nas séries iniciais tendo como base alguns artigos (encontrados no Scielo, portal CAPES, banco de dados da USP, UNICAMP, PUCRGS, entre outras fontes ONLINE), e também em autores como: Strieder (2002), Assman (2012), Vaillant (2012), Freire (1996), Morin (2000) e outros. Segue-se em seu delineamento, a pesquisa bibliográfica.

\section{Desafios da educação humanizadora com o uso das tecnologias}

De certo modo, a educação se apresenta como excludente e não integrante, não desejante, não acolhedora, em alguns locais as tecnologias e os métodos das aulas continuam iguais, há casos em que os alunos com necessidades especiais, em várias situações eles são simplesmente 'inseridos’ no contexto escolar, mas não são notados. Se não tiver o professor que assuma uma postura de educador na criação dos processos educativos não adianta novas práticas pedagógicas de inclusão. Assim também pensava Assmann (2012), que os processos educacionais precisam: "reencantar a educação significa colocar a ênfase 
numa visão da ação educativa como ensejamento e produção de experiencias de aprendizagem" (ASSMANN, 2012, p. 29).

O fato é que ainda as nossas escolas são do século 19 sem nenhum avanço, professores do século 20 e em muitas circunstâncias sem possibilidades de se capacitarem e os nossos alunos do século 21 bombardeados de informações da mídia e das redes sociais. A escola que todos sonham é aquela que consegue integrar todas as culturas, etnias, credos e orientações sexuais em um ambiente só, que demonstre carinho e afeto a todos sem nenhuma distinção. Uma escola humanizadora sem nenhuma dúvida é aquela que consegue envolver seus educandos com seus modos de viveres, assim integra-os uns aos outros. Pensar em uma escola acolhedora, essa é a ideia de uma educação humanizadora:

Os métodos clássicos de tortura escolar como a palmatória e a vara já foram abolidos. Mas poderá haver sofrimento maior para uma criança ou um adolescente que ser forçado a mover-se numa floresta de informações que ele não consegue compreender, e que nenhuma relação parecem ter com sua vida? (ALVES, 1994, p. 13-14).

As escolas assim como todos os ensinamentos nela ministrados devem ser para uma educação humanizada, buscar a realidade dos educandos é trabalhar com sentimentos, pois segundo Strieder: "humanizar requer manter acesa a chama da vivência criativa, regada pela afetividade, pela sensibilidade, pelo riso, pelas lágrimas, pelo fervor da participação, pelas luzes do respeito e pelo desejo de cultivar, no jardim da vida, a vivência da beleza" (2002, p. 13).

A pedagogia afetiva ou humanizadora estabelece relação de afetividade, acolhimento e cumplicidade na relação aluno e professor. Deve ocorrer uma troca de experiência afetiva imprescindível. O professor/educador deve se sentir responsável pelos seus educandos, desta forma inicia um laço de familiaridade dentro da sala de aula, assim ficara mais fácil de trabalhar com seus alunos, cria-se um papel de facilitador de aprendizagem. Desta maneira prioriza as relações de respeito e reciprocidade. Para Strieder (2002, p. 201), “a educação efetivamente comprometida com o salvamento das vidas de todas as gentes tem que responsabilizar-se pela recriação dos ambientes educacionais”. Deve-se incluir em uma 
escola humanizadora a recreação educacional, pois é uma prática prazerosa e instigante para o docente ao encontrar-se na sala de aula. Uma ferramenta 'simples' com resultados fascinantes e com um processo de socialização instigador. Pois o processo se inicia na escola juntamente com a sociedade integra-se práticas para que possam ser utilizadas no dia-a-dia da criança:

\begin{abstract}
$\mathrm{Na}$ escola, pelos conhecimentos e pelo desenvolvimento das competências cognitivas, torna-se possível analisar e criticar a informação. Os alunos vão aprendendo a buscar a informação (na TV, no rádio, no jornal, no livro didático, nos vídeos, no computador, etc.) mas, também, os instrumentos conceituais para analisarem essa informação criticamente e darem-lhe um significado pessoal e social. A escola fará, assim, a síntese entre a cultura formal (dos conhecimentos sistematizados) e a cultura experienciada. Por isso, é necessário que proporcione não só o domínio de linguagens para a busca da informação, mas também para a criação da informação. Ou seja, a escola precisa articular sua capacidade de receber e interpretar informação, coro a de produzi-la, considerando se o aluno sujeito do seu próprio conhecimento" (LIBÂNEO, 2001, p. 7).
\end{abstract}

O processo de humanização está relacionado com o interior de cada um, da busca por ser uma pessoa melhor, onde há um clima harmonioso, capaz de despertar sentimentos inesperados. As questões culturais envolvem a aceitação e o respeito nas demais que o cercam implicam também como fator para uma educação de melhor compreensão. A emoção é fator de resistência a qual deve ser compreendida e interpretada pelo docente para que assim possa ser um ‘auxilio' no aprendizado.

Uma relação humanizada em que os indivíduos não precisam estar de acordo com tudo, mas sim respeitar os pensamentos e falácias de seus colegas, desta maneira porquê não integrar este processo de humanização nas escolas, não seria mais fácil e agradável para os alunos fazer parte de uma escola acolhedora, que trate todos com igualdade sem distinção, de cor, credos e orientações sexuais ou etnia. De acordo com Strieder (2002, p. 242) "crescem os alunos aprendendo e vivendo o individualismo e a não necessidade de estabelecer correlações com as demais disciplinas, como também de não ver a necessidade do outro para que ele seja o que é”. 
A emoção que funda o social como a emoção que constitui o domínio de ações no qual o outro é aceito como um legítimo outro na convivência é o amor. Relações humanas que não estão fundadas no amor - eu digo - não são relações sociais. Portanto, nem todas as relações humanas são sociais, tampouco o são todas as comunidades humanas, porque nem todas se fundam na operacionalidade da aceitação mútua. (MATURANA, 2002, p. 26).

Educadores precisam ter habilidade em despertar a vontade e a necessidade de seus educandos de aprender. Precisam transformar o aluno a ser um instigador, um descobridor e desbravador dos valores de seus conhecimentos. Que a cada descoberta vire uma maneira de transformá-las em novas ideias e opiniões, deste modo forma-se um ser crítico.

É difícil educar para a aceitação e o respeito de si mesmo, que leva à aceitação e ao respeito pelo outro, assim como à seriedade no fazer? Não, só que isto requer que o professor ou a professora saiba como interagir com os meninos e meninas num processo que não os negue ou castigue, seja pela forma como eles aparecem na relação, seja porque não aparecem como as exigências culturais dizem que deve ser. Esse professor ou professora pode fazê-lo porque, eles também, respeitam a si mesmo e ao outro. (MATURANA, 2002, p. 32).

A sociedade tem ligação direta nas informações veiculadas em televisão, jornal, rede social com isso é um meio que os educandos captam as notícias sem averiguar ao certo a veracidade, por isso a tamanha importância da escola e do professor. Temos como exemplo o jogo Baleia Azul, que acontece pelas redes sociais onde são lançadas tarefas aos participantes e no final leva à morte, que está tão comentado nos últimos tempos, muitas vezes quem entra nesse jogo e acredita ser real as ameaças, falta um pouco de instrução, de apoio, às vezes por influência de amigos as ditas 'modinhas' que os jovens dizem ser seguidas, com auxílio de um adulto, o professor instruir, quem sabe esse ser crítico não se deixe levar por notícias falsas.

A escola surge como um antídoto à ignorância, logo, um instrumento para equacionar o problema da marginalidade. Seu papel é difundir a instrução, transmitir os conhecimentos acumulados pela humanidade e sistematizados logicamente. O mestre-escola será o artífice dessa grande obra. A escola se organiza, pois, como uma 
agência centrada no professor, o qual transmite, segundo uma gradação lógica, o acervo cultural aos alunos. A estes cabe assimilar os conhecimentos que lhes são transmitidos. (SAVIANI, 1999, p. 18).

Instigar os educandos a curiosidade, a aguçar novas leituras e sua capacidade de dominar algumas áreas do conhecimento, desta forma consegue-se solucionar alguns problemas simples do cotidiano fora ou dentro da sala de aula. Trazer a realidade para a sala de aula, falar de suas vivências, deste modo trabalha-se uma educação humanizada, trabalha com sentimentos, que é tão difícil de ver nas escolas, mas com tantas formas, metodologias e habilidades para auxiliar os professores. A bagagem dos alunos muitas vezes é maior do que imaginamos, por isso deve-se investigar e coletar vestígios que possam servir de auxilio nos conteúdos, pois se o aluno já sabe algo sobre o conteúdo comentado, certamente isto facilita sua aprendizagem, e contribui na aula, desta maneira se estabelece mais diálogo entre o aluno-professor e vice-versa.

Pois o que vocês ensinam não e um deleite para a alma? Se não fosse, vocês não deveriam ensinar. E se é, então é preciso que aqueles que recebem, os seus alunos, sintam prazer igual ao que vocês sentem. Se isso não acontecer, vocês terão fracassado na sua missão, como a cozinheira que queria oferecer prazer, mas a comida saiu salgada e queimada... (ALVES, 1994, p. 10).

Quebrar o paradigma da transmissão do conhecimento, pois a escola não é um banco onde se deposita informações prontas e acabadas, passadas de forma friamente. Deve-se pensar em ensinar com os sentimentos, de que maneira você vai formar o aluno para que seja um adulto consciente de seus atos. A sociedade que a cerca influencia muito no modo de ser e suas ações, cabe ao professor auxiliar no recebimento das informações para que possam ser melhor interpretadas. Moldar as informações, orientar para seguir a direção correta, sempre destinar da melhor maneira para que os alunos possam seguir o caminho do bem e saibam fazer suas escolhas de forma correta e justa.

É isto que nos leva, de um lado, à crítica e à recusa ao ensino 'bancário', de outro, a compreender que, apesar dele, o educando a ele 
submetido não está fadado a fenecer, em que pese o ensino "bancário", que deforma a necessária criatividade do educando e do educador, o educando a ele sujeitado pode, não por causa do conteúdo cujo "conhecimento" lhe foi transferido, mas por causa do processo mesmo de aprender, dar, como se diz na linguagem popular, a volta por cima e superar o autoritarismo e o erro epistemológico do 'bancarismo’. (FREIRE, 1996, p. 13).

Uma escola humanizadora, vai além de todos os critérios para alcançar uma educação de qualidade e afetiva, é muito mais harmoniosa e acolhedora. É permitir deixar seus alunos se aventurar em um mundo só deles, com descobertas e surpresas, deixá-los ousar, ultrapassar, assim descobre-se novas fronteiras, desta maneira o aluno terá grandes oportunidades de ser o que ele deseja, não o que a sociedade impõe para ele.

O respeito, solidariedade, compreensão são alguns dos saberes e valores que devem estar incluídos na convivência escolar, uma escola acolhedora com uma base bem estruturada, que reconheça as qualidades e também dificuldades dos seus alunos, o ato de perceber a maneira de pensar e agir do outro traz resultados positivos, desta forma se obtém uma melhora no desenvolvimento de seus estudantes. Segundo Strieder (2000, p. 234) "a educação não pode perpetuar a construção de verdades, com base na negação dos outros, sempre fonte geradora de ódios. Sejamos então o caldeirão do caminho da liberdade albergado na criação, operando no amor e energizando o prazer pela vida”.

Há escolas que não estão preparadas para atender alunos do século XXI, pois a escola está ainda no método do século XIX, há uma grande dificuldade de acompanhar as novidades diárias, que seus alunos estão habituados. As escolas estão rodeadas de informações e conhecimento, maioria não consegue dar conta de como mediar para seus educandos, estes conceitos aguçam a curiosidade, despertam o encanto de uma poesia ou poema, que valorize a arte, problematize a matemática de uma maneira simples que cative a atenção e a admiração dos alunos, desta forma a escola possivelmente tem condições de tornar o lugar mais agradável, com momentos únicos e instigadores, de aventurar-se, contar sua própria história sem medo de ser recriminado, falar de suas vivências e de seus sonhos. A 
escola humanizante visa desta maneira, que seja feito de uma forma educativa ao mesmo tempo, que tudo o que foi falado vire aprendizado, que nada seja atoa.

Segundo Assmann (2012, p. 29), “o ambiente pedagógico tem de ser lugar de fascinação e inventividade. Não inibir, mas propiciar, aquela dose de alucinação consensual entusiástica requerida para que o processo de aprender aconteça como mixagem de todos os sentidos." A escola tem um grande vínculo com a sociedade, isso não temos nenhuma dúvida, uma das grandes dificuldades é como conseguir acolher os educandos, fazê-los superar seus medos, seus anseios, suas angustias, seus desejos, muitas vezes os professores com a imensidão de alunos ao seu redor, não enxergam, mas é fundamental e humanizador constituir essa visão de que o professor deve possuir em sala, muitas vezes o aluno está com problemas pessoais, justifica o motivo da nota baixa.

A escola se responsabiliza diante de um mercado de trabalho competitivo a formar profissionais competentes, formar mão de obra para o mercado de trabalho. As tecnologias estão de fácil acesso, hoje em dia, os alunos mudaram o pensamento e a forma de aprender usando-as, mas falta o professor rever o seu modo de ensinar. Quando se fala e pensa na formação, promove-se a transformação, crítica e criativa. E é neste processo de formação que não se deve admitir falhas de ensino, pois é a fase onde o aluno tem para alinhar as informações e conhecimentos adquiridos, por isso os professores devem tomar cuidados e estar em constante atualização e estudo.

Talvez valha a pena tentar a mesma estratégia, que hoje oculta violentamente a perspectiva solidária e expõe em forma de crença o princípio do conflito e do egoísmo. No lugar da eterna ostentação de que somos adversários, toda vez que precisamos comparecer a pontos de encontro, cabe iniciar processos de convivência efetiva que conjugue a face das adversidades com as também existentes faces da colaboração solidária. (STRIEDER, 2002, p. 193).

Reflete-se sobre o mundo atual, assim é possível analisar o quão difícil está para as crianças desejarem ir à escola, pois a escola passou a ser um lugar não desejante, por isso, a urgência no pensar em novas metodologias ou caminhos de ensino e aprendizagem. Quem sabe esse mergulho nos processos educativos com a inclusão das tecnologias, seja a 
possibilidade que os cative. Implantar-se o uso das tecnologias pode-se comparar aos jogos e lançar desafios no computador para que se vá em busca de respostas, o professor passa respostas prontas e não instiga o conhecimento do aluno, instiga-se os alunos a ir em busca de aprofundar sobre determinado assunto para formar assim o seu pensamento, deste modo será um ser crítico e construirá sua personalidade.

Cada aluno chega a escola com uma cultura e identidade própria, o professor como mediador deve moldar e auxiliar para que cada educando construa o seu ser crítico e traços sociais onde possa se destacar e saber sobreviver nessa sociedade que vivem, ser mais humano e compreender tudo o que o cerca, pensar desta maneira supera-se as barreiras que a sociedade constrói. Cada um nasce em uma família diferente a qual segue suas rotinas e culturas, mas todas as famílias têm amor e sentimentos para com o próximo, e a educação humanizadora busca justamente esse sentimento de gratidão e amor entre professores, pais e estudantes.

Durante o processo de planejamento das aulas precisa-se refletir sobre a própria condição humana que é oferecida aos profissionais em educação, trabalhar em um contexto gélido de sentimentos e de auto realizações, deixar que o aluno questione, pesquise sobre as dúvidas assim transformará a informação conforme seu entendimento e exponha aos colegas, diversos fatores podem ser trabalhadas em cima de uma simples pesquisa de um educando, a oralidade e postura na hora da apresentação, por exemplo, assim ele se interessa sobre o assunto que sugeriu e iniciou a pesquisa e o professor com o papel de transformador conclui com o conhecimento científico acerca do assunto.

Pensar em políticas públicas que incentivem e criem cursos de formação para utilização. Busca-se ferramentas simples e adequadas as idades das crianças, estimular a resolver problemas e trabalho em equipe, ter paciência, desenvolver capacidade de ouvir os outros, de receber críticas, o aluno sentira prazer em estudar e ir em busca pelo novo, assim terá capacidade de autoria, a criança é criativa basta deixar a criatividade fluir, não se deve limitála a ler, escrever e memorizar, pois estará ‘matando' um ser crítico e criativo. O computador é um recurso tecnológico, que cuja eficácia e resultado dependem de quem está por trás, 
ou seja, o professor deve estar capacitado, desta forma o aluno terá um melhor entendimento e vontade de cada vez mais adquirir conhecimento.

Tornar o ensino significativo é criar pontes entre o novo conhecimento e o conhecimento que os alunos já possuem. Esse é uma tarefa possível e até simples de realizar para o professor que tem domínio e conhece as especificidades de sua disciplina. Uma pergunta bem-feita, um fato ou história, uma notícia do jornal, uma reportagem, a natureza, o próprio contexto em que os alunos estão inseridos pode ser o agente estimulador da aprendizagem. A forma como se faz não importa, o que é importa mesmo é despertar a "sede", a vontade de aprender. (FONSECA, 2008, p. 29).

A educação é influenciada querendo ou não, com a tecnologia. Basta integra-la ao meio social, o professor se torna um elo entre educação x tecnologia, esses recursos devem ter um objetivo único, a utilização no processo de ensino nas séries iniciais. É uma tarefa que não acontece do dia para a noite, mas sim, se introduz aos poucos e consegue um resultado positivo tanto para educando como o educador, assim fascina-se o aluno para novas descobertas. E que essas descobertas sejam estradas para o conhecimento e para o viver na diversidade.

Percebe-se o quanto foi e é importante o uso da tecnologia na sala de aula o uso da TV $, D V D, D A T A S H O W$ entre outros. Pode-se ainda, incluir o uso de aparelhos celulares na sala de aula, basta saberem o uso no momento correto e de que modo o utilizar. O uso da calculadora, por exemplo, se utilizada corretamente é benéfica para a aprendizagem no aluno. Muitas são as formas de incrementar a tecnologia na sala de aula, ajuda na hora do trabalho com a pesquisa online, gravações de vídeos, teatros ou até mesmo fotografia, é uma maneira fácil e interessante. Entretanto, não são esses recursos, que constrói uma educação humanizadora, ela é muito mais que isso. Ela transforma vidas a partir do momento que for internalizado os aspectos formativos.

As tecnologias, quando inseridas na área educacional, requer mudança de atitude dos professores. Muitas vezes, provocam uma reviravolta nas atitudes dos mesmos, no seu comportamento, que resistem ao seu uso. Os avanços tecnológicos trazem novas exigências 
à formação de professores e muitos professores, submissos ao modelo antigo de educação, têm dificuldades em manipular e incorporar os recursos tecnológicos ao processo de ensino e de aprendizagem. (ALTOE; FUGIMOTO, 2009, p. 166).

A tecnologia surge como modo de facilitar a vida e algumas tarefas que são impostas, na área educacional se entende como ferramenta de auxilio nas dificuldades de aprendizagem, sendo como 'caminho para o conhecimento', abrindo portas para um futuro promissor e para formar cidadãos mais conscientes e críticos, desta maneira vê-se a grande importância da inclusão na sala de aula para melhor contribuir com as práticas pedagógicas.

A palavra tecnologia é de origem grega: tekne e significa "arte, técnica ou ofício". Já a palavra logos significa "conjunto de saberes". Por isso, a palavra define conhecimentos que permitem produzir objetos, modificar o meio em que se vive e estabelecer novas situações para a resolução de problemas vindos da necessidade humana. Enfim, é um conjunto de técnicas, métodos e processos específicos de uma ciência, ofício ou indústria. (RAMOS, 2012, p. 4).

Mudanças, transformações, estar aberto a inovações, falta de formação aos docentes, pois não existem capazes ou incapazes de ensinar com o uso da tecnologia, o professor precisa ser contagiado, pensar que o mundo atual necessita desta atualização, que as crianças se identificam cada vez mais com as tecnologias pelos benefícios: informação rápida, dinâmica, estímulos e por questões de afetividade e razão.

Um novo conteúdo curricular tem urgência em pervagar todas as atividades pedagógicas e educacionais. É preciso estar aberto para as coisas novas e iniciar-se no mundo da criatividade. O mundo profissional, para além da ótica empregatícia, perfila-se como impostergável no atual contexto de desemprego em massa. (STRIEDER, 2002, p. 271).

O processo é lento e complexo, fatores implicam no meio do caminho como conflito de pensamentos, pois o virtual faz com que tenham uma imaginação fluente, assim cada um construirá uma visão, o professor terá papel de auxiliar na aceitação do olhar do outro e que está opinião auxilie na construção pessoal, motivar as crianças com a aprovação 
de suas opiniões para que possa despertar o interesse em querer ir em busca de mais conhecimento. Construir ideias a partir de diversas situações, o ser autônomo e decidir o que pensa ser melhor para si naquele momento, assim como incluir os computadores e aceitalos da mesma maneira terá construção de ideias dos colegas e inclusão de colegas com deficiência.

A introdução dos computadores na escola iniciou-se pela secretaria para uso de processos burocrático-administrativos, mais tarde obteve-se na biblioteca para controle de empréstimo dos livros, e pensado para a aproximação do aluno, foi se implantado nas salas de informática, mas essas pouco restrita, com horários marcados, os alunos estariam em monitoramento por um professor responsável. Percebe-se o quão difícil é acompanhar a evolução da tecnologia, pois nas escolas deve-se seguir um processo burocrático que depende de superiores para que possa seguir com projetos como o da inclusão das tecnologias.

O mundo dos desejos e o mundo das esperanças encontram sua gênese instituinte, realizante ou frustrante, na simbologia das linguagens e no contexto no qual as concebemos. Sonhos, esperanças e desejos são assim indissolúveis do nosso. plano biofísico e social/humano. (STRIEDER, 2002, p. 39).

Não basta colocar computador com internet na escola, temos o fator da pouca leitura que é relevante na população brasileira, dificulta-se o processo de pesquisa e obtenção de informações na rede. Por essa falta de leitura, as vezes abre-se a internet para pesquisa de trabalhos e a prática de plagio vem à tona, pois falta incentivo à leitura, assim fica mais fácil 'copiar e colar' e o trabalho está pronto. Um exemplo presenciado no dia-a-dia é o uso da calculadora, que muitas vezes leva o ser humano a não saber calcular sem a ferramenta, se torna dependente da máquina. Precisa-se de novos laboratórios de pesquisas, novos canteiros no investigar para assim se integrar e se incluir essas práticas com o uso de recursos tecnológicos. 
A escola com seu papel principal neste processo é preciso que se envolvam os gestores, professores, coordenação e todos os funcionários até mesmo pais para que seja inserido as tecnologias em todo contexto educacional pois a escola não pode ignorar o que acontece no mundo, pois esse avanço colabora no trabalho, nas decisões pessoais e profissionais e até mesmo na forma como as pessoas pensam, quanto mais informado o aluno estará melhor será o seu desempenho e aprendizado.

É básico que todos os envolvidos na educação, docentes e discentes, construam linguagens pedagógicas cujos campos de significados permitam que eles se sintam bem para que o desafio do aprender seja recompensado pela alegria do viver melhor. No entanto e como se percebe nos ambientes escolares a indiferença quanto ao saboreamento da vida é ainda algo tornado soberano. (STRIEDER, 2002, p. 238).

A inserção tecnológica torna-se um processo significativo na escola quando consegue envolver a comunidade em geral, portanto é democrático, para que esse uso das tecnologias seja feito de forma mais acessível precisa envolver pais e comunidade em geral, mostrar os projetos e como funciona na escola, desenvolver noites culturais para que seja apresentado o avanço da aprendizagem dos alunos, desta maneira, se perceberem o avanço pode-se cativar para que mais pessoas se interessem por pesquisa e estudo, os educandos montar 'aulas' para demonstrar o que aprenderam nas aulas com o uso destas tecnologias, mini projetos que incentivem cada vez mais a busca pela informação, está clara, aprofundada e de fonte confiável.

\section{O papel do professor no desafio tecnológico}

A educação estava moldada como forma tradicional, constituía-se em memorização e repetição de ensinamentos prontos, mais tarde passou-se a estimular mais o aluno para liga-lo à realidade, estimular o ser pensante em cada educando, ainda existem muitas dificuldades no acesso as novas tecnologias, influenciam e mudam a vida das pessoas com o avanço e desenvolvimento acelerado, desta maneira é um importante instrumento de informações e busca por cada vez mais conhecimento. Professor tem que estar ciente que 
tem a difícil tarefa de se adaptar a este 'novo mundo' tecnológico onde devido à necessidade criada ninguém mais consegue viver sem.

A afetividade pode asfixiar o conhecimento, mas pode também fortalecê-lo. Há estreita relação entre inteligência e afetividade: a faculdade de raciocinar pode ser diminuída, ou mesmo destruída, pelo déficit de emoção; o enfraquecimento da capacidade de reagir emocionalmente pode mesmo estar na raiz de comportamentos irracionais. (MORIN, 2000, p. 20).

Docente deve aliar o conteúdo aos recursos à disposição para que possa ministrar uma aula desejante que cative os alunos a ter vontade de ir além do conhecimento passado, ou seja, abrir-se para uma nova aventura humana, a do conhecimento, buscar e construir conceitos próprios do assunto. Aprender assim a serem pessoas críticas, que pesquisam e investigam, não aceitam as verdades prontas, tem sede do saber.

Nova consciência começa a surgir: o homem, confrontado de todos os lados às incertezas, é levado em nova aventura. É preciso aprender a enfrentar a incerteza, já que vivemos em uma época de mudanças em que os valores são ambivalentes, em que tudo é ligado. É por isso que a educação do futuro deve se voltar para as incertezas ligadas ao conhecimento" (MORIN, 2000, p. 84).

Frente as novidades pode-se observar um professor que deseja incorporar essas novas tecnologias para acompanhar esses avanços e temos a insegurança pela falta do preparo, mas deve-se saber interagir com o aluno, pois os mesmos também tem muita coisa a ensinar para o professor, aqui tens exemplo de uma escola desejante, onde todos aprendem uns com os outros, trabalho em equipe onde professor e alunos trabalham juntos, o educador que estiver disposto a buscar e receber informações conseguirá transmitir ao educando de uma forma que aprendam, e desperta-se interesse pela pesquisa, e aprofunda-se com essas informações criar os próprios conhecimentos, sua personalidade, auxilia na formação de valores. Os professores devem acompanhar a mudança do mundo, auxiliar os alunos com tarefas agradáveis e que sejam pessoas capazes de resolver os próprios problemas, confrontar-se e desafiar-se a todo instante. 
A perspectiva da sensibilidade de inclusão do outro e não a sua exclusão, precisa ser articulada a partir da ótica de uma sensibilidade cooperativa impedida e, portanto, não in-existente. Talvez ela esteja submersa no formidável auto-engano que continua impedindo uma revisão geral de nossa responsabilidade junto ao outro. Historicamente a capacidade desejante da sensibilidade inclusiva, veio sendo anulada e, os humanos, nos tornamos vitimas sufocadas dessa capacidade desejante. (STRIEDER, 2002, p. 183).

Além disso, pode-se perceber a resistência por parte de alguns professores em utilizar os novos recursos tecnológicos, os motivos são variados, muitas vezes por insegurança, medo, falta de capacitação, ou até mesmo por falta de estrutura e equipamentos na unidade escolar em que atua. Tecnologias de Informação e Comunicação (TIC) na sala de aula aliadas ao plano de ensino do educador fazem a diferença na qualidade da educação, as crianças sabem cada vez mais utilizar as tecnologias, com isso os professores interagem nas aulas com os educandos, ao trabalhar em equipe, juntar os saberes para ensinar e aprender de uma forma mais criativa e dinâmica.

As investigações recentes sobre formação de professores apontam como questão-chave o fato de que os professores desempenham uma atividade teórico-prática. É difícil pensar na possibilidade de educar fora de uma situação concreta e de uma realidade definida. A profissão de professor combina sistematicamente elementos teóricos com situações práticas reais. Com essa razão, se pensar um currículo de formação, a ênfase na prática como atividade formadora aparece, à primeira vista, como exercício formativo para o futuro professor. (LIBÂNEO, 2011, p. 93-94).

De acordo com Assmann (2012, p. 40), “o aprender não se resume em aprender coisas, se isto fosse entendido como ir acrescentando umas coisas aprendidas as outras, numa espécie de processo acumulativo semelhante a juntar coisas num montão.” A utilização de novas tecnologias nas aulas muitas vezes é vista como impossível por vários fatores como: inquietação dos educandos, uso das redes sociais atrapalhando a aula, falta de atenção. Mas, todavia, se for um fator que souber ser implantado aos poucos, utilizar métodos 
adequados será bem-sucedido, sabe-se que nada é fácil quando é novo, com tempo certo adaptações e adequações necessárias o processo se inicia e obtém resultados positivos.

O grande desafio é transformar as informações, pois os alunos têm acesso á estas, mas muitas vezes, não tem maturidade suficiente para coletar e organizar as mesmas, mas cabe ao professor auxiliar neste processo, despertar a curiosidade e a criticidade, cria-se um ambiente favorável aos debates dos assuntos para que cada um desperte o ser crítico e seja receptor e construtor do conhecimento assim torna-o responsável e comprometido, fazer do processo mais interessante e dinâmico.

A profissão do professor pode ser comparada ao engenheiro, constrói a ponte, convidam os educandos á atravessarem e após derruba covardemente para que os alunos criem estratégias e construam a ponte para poder voltar ao local de origem. Segundo Junckes, (2013, p. 1) "a atuação dos profissionais da área de educação vem se remodelando com a finalidade de atender às demandas dos alunos, não só transmitindo conhecimento, mas buscando a interação e estimulando os alunos para desenvolverem suas habilidades e concretizarem iniciativas e sonhos".

As aulas tornam-se dinâmicas quando se aprende como usar as tecnologias. Alguns professores temem ser substituídos pelas tecnologias, outros casos falta a estrutura e acesso, mas deve ser pensado que é o suporte, ferramentas facilitadoras e usa-las nas aulas, estimular os educandos. Construir com o uso das tecnologias espaços laborais para despertar nas crianças o desejo de criatividade.

Já citava Freire (1996, p. 88) "o mundo encurta, o tempo se dilui: o ontem vira agora; o amanhã já está feito. Tudo muito rápido. Debater o que se diz e o que se mostra e como se mostra na televisão me parece algo cada vez mais importante." Em um mundo onde tecnologia avança a todo instante, o docente deve aliar a realidade do aluno, refletir e analisar as práticas da escola e sociedade, quanto mais próximo a realidade do aluno, maior será seu aprendizado, pois o mesmo se interessara pelo assunto proposto, pois já tem um pouco de conhecimento e com certeza utilizara a internet a ir em busca de aprofundamento. 
A finalidade da formação humana é o fundamento de todo processo educativo. É por meio dela que se pretende desenvolver a prática do autoconhecimento em cujas pessoas passem a ver que possuem a capacidade de encarar a adversidade sendo holísticas e independentes e reconhecerem a interdependência entre os seres. Pessoas que estejam sempre dispostas a responder por que e porque não, que encontrem possibilidades de colocar sua visão de mundo e suas ideias num contexto mais amplo, com espontaneidade, compaixão e a consciência de seguir as próprias ideias além de questionar as convenções, não com o sentido ingênuo de fomentar a discórdia e a rebeldia, mas consciente de seus propósitos. É assim que podemos pôr nossos atos e nossa vida em um contexto mais amplo e com a qual avaliamos se uma ação faz mais sentido do que outra. É esse poder transformador que diferencia os indivíduos. (MACIEL, 2009, p. 4).

O docente é o facilitador do ensino, deve estar preparado para ajudar interpretar as informações recebidas pelos educandos, ampliar sua visão de mundo, atentar-se nas informações da mídia manipuladora, consumista e que não vai ao encontro dos valores humanos. $\mathrm{Na}$ formação humana deve levar em consideração a autoaprendizagem, o processo de descobrimento, envolver sentimento na aprendizagem, educação para a sensibilidade, pois quem sente alegria com uma descoberta com certeza aprendeu. Aprende-se muito com as emoções.

\section{O contexto educativo e a formação dos professores: resultados de uma nova práxis} pedagógica

O processo deve ser aprendente, que se constrói ao longo do percurso, pois não se aprende somente com a escola e sim com a vida e com a sociedade. A sociedade é massa manipuladora e que mais influencia as crianças, pois todo momento se tem informações sendo elas verdadeiras ou não, a escola entra nesse meio auxiliando as "mentes pouco instruídas" para atribuir real sentido ao que ouve nas mídias e na sociedade que o cerca. Pois, para os políticos mente pouco instruída é mais fácil de manipular, sendo assim o processo de falcatruas pouco é mencionado, basicamente os seres humanos servem para o trabalho e votação para eleger os governantes. 
A sociedade se constitui como sendo da informação, mas se esta for vazia sem muitas fontes não é válida, cabe ao educador transformar esta realidade para que aos poucos seja uma sociedade do conhecimento. "Seres vivos são seres que conseguem manter, de forma flexível e adaptativa, a dinâmica de continuar aprendendo.” (ASSMANN, 2012, p. 22).

As sociedades domesticam os indivíduos por meio de mitos e ideias, que, por sua vez, domesticam as sociedades e os indivíduos, mas os indivíduos poderiam, reciprocamente, domesticar as ideias, ao mesmo tempo em que poderiam controlar a sociedade que os controla. (MORIN, 2009, p. 29).

Considera-se um desafio incorporar tecnologia na sala de aula, deve se articular a tecnologia para melhores resultados em termo de qualidade e satisfação na área educacional. Os estudos do projeto constam práxis pedagógicas acerca da escola pública e privada ao encontro de uma inclusão tecnológica nos meios sociais e contextos educativos atuais:

Entende-se por tecnologia educacional, o conjunto de técnicas, processos e métodos que utilizam meios digitais e demais recursos como ferramentas de apoio aplicadas ao ensino, com a possibilidade de atuar de forma metódica entre quem ensina e quem aprende. Quando se pensa as tecnologias em Sala de Aula, vem à ideia e muito dos estudos falam sobre as TIC (Tecnologias de Informação e Comunicação). (RAMOS, 2012, p. 6).

$\mathrm{Na}$ atualidade as redes eletrônicas, tais como celulares, internet e redes sociais estão a invadir a sociedade, geram-se desta forma uma mudança de comportamento e atitude. E não está diferente na sala de aula, alunos bombardeados de informações e descobertas querendo utilizá-las em seu ambiente escolar. A insistência de seus mestres em não usarem em sala de aula, mesmos para fins educativos. É o que acontece na maioria das escolas:

O que tem a ver tudo o que foi dito anteriormente com a formação dos docentes? cremos que muito. A formação hoje em dia é formação individual e social. Mas se requer desenvolver em todas as pessoas, especialmente nos docentes, a capacidade de autoformação, a capacidade de delinear e desenvolver processos de aprendizagem ao 
longo da vida, utilizando em cada momento os meios mais apropriados e eficazes" (MARCELO; VAILLANT, 2012, p. 32).

O educando procura a escola com sede do aprender, mas essa sede deve ser alimentada a cada dia, é preciso cativá-los, mostrar interesse e vivências novas para que esse conhecimento se torne cada vez mais possível, professor mediador, a base deste aprendizado, a escola pode até não ter os recursos necessários para se ter novas tecnologias incluídas em sala mas a criatividade do professor neste momento 'fala mais alto', é o que move o prazer em aprender, pois pessoas críticas e criativas formam pessoas excelência em criatividade e criticidade.

O professor precisa colocar-se como um ser atento, sensível, pronto a perceber as dificuldades, anseios, desejos de seus alunos e atuar instigando os alunos para que despertem o olhar ao outro. Essa escola se reconhece como um lugar de encontros, um lugar de humanização, de sensibilidade, um lugar de vida e de diversidade. (STRIEDER; ZIMMERMANN, 2012, p. 110).

Deve-se valorizar as crianças, as suas falas e criatividade, jamais deve corrigir arduamente as crianças e sim fazer com que percebam seus erros para que possam buscar corrigi-los, e a internet contribui neste processo sendo ferramenta de investigação, auxiliar na busca das respostas e no aprofundamento do conteúdo. O professor deve aceitar a opinião de seus alunos, ajudá-los a instigar os seus medos e ultrapassar seus desafios. Desta maneira o professor não terá um aluno na sala de aula, mas sim um amigo, é essa amizade, harmonia que muitas vezes fazem a diferença no ensino mostra-se a afetividade e acolher para o estudo.

A forma tradicional da estrutura da escola e de ensinar é um fator negativo quando se fala em inovação e tecnologias, pois é difícil mudar algo que vem de anos, mas nunca é impossível, deve-se trabalhar para mudar o pensamento destes tradicionais de que uma das causas de os alunos reprovarem também pode ser essa forma tradicional sem muitas alternativas na aula, causando assim a falta de compreensão dos conteúdos. Sala de aula deve ser lugar desejante, instigante que o aprendente tenha prazer em entrar e sentir que é um 
local bom para estudos, por isso a educação envolve muito sentimento, afetividade para que se sintam bem e aprendam com facilidade.

Hoje, os professores se deparam com uma sala de aula onde falta algo a ser articulado, falta concretizar o conhecimento de seus educandos, incluir novos meios de tecnologia assim quebra-se os paradigmas de escola tradicional. Falta incentivo e muitas vezes recursos, até mesmo estrutura em algumas escolas, mas se tiver força de vontade e concretar as iniciativas aos poucos será alinhado e com certeza fará a diferença. Pois já dizia Strieder e Zimmermann (2012, p. 18) “o convite não é para olhar uma situação e negar a outra, mas reconhecer que é preciso dar-se conta que há um processo de integração há mudanças positivas acontecendo nas sociedades humanas."

Os sujeitos envolvidos no processo de educação são muitos, mas diretamente ligados à alfabetização é o professor mediador, o que deve mediar o ensino com metodologia diferenciada, o conhecimento e entendimento dos alunos, mas para que o processo tenha cada vez mais êxito, propõe-se que os sujeitos envolvidos nesse meio também possuem uma instrução, estudo de conhecimentos e que saibam usar um pouco das tecnologias que tem a disposição em todos os locais, a coordenação e direção da escola desenvolver estratégias para que os professores possam ter formação continuada e cursos para que saibam lidar com as tecnologias, para isso Vaillant e Marcelo citam que:

Malcon Knowles desenvolveu uma teoria sobre a aprendizagem adulta, denominada Andragogia, em outras palavras propõe que uma pessoa adulta desenvolva uma concepção sobre si mesma, que utilize sua experiência como recurso para sua aprendizagem e que se motive a aprender em função dos papéis sociais que desenvolve. (VAILLANT; MARCELO, 2012, p. 28).

É preocupante quando se sabe que há espaço para introduzir a tecnologia, mas por causa de alguns fatores não se for feito, medo, insegurança, e muitas vezes 'cortar as asas de quem quer voar', os sonhos dos alunos que querem utilizar os recursos para o aprendizado, é deprimente quando os professores analisam que é perca de tempo toda a inclusão, de que de nada adianta fazê-la. A escola privada tem condições de se ter bem mais recursos, 
mas não se sabe ao certo se utiliza de forma correta ou usa-se todos os recursos disponíveis pois ferramentas excelentes existem e estão à disposição no processo de ensino aprendizagem.

Por vezes a classe dos professores é desvalorizada por diversas situações, mas se presenciam várias cenas de que muitas vezes os alunos se relacionam melhor com os professores do que com familiares, a sociedade deve analisar e pensar se existem todos os profissionais é porque existe professor que busca sempre novos recursos para que isso se torne possível.

Oliveira e Harres (2017) na experiência de um grupo de professores que criaram um projeto utilizando o Facebook como ferramenta de auxílio na educação percebe-se que em alguns casos realmente auxiliam de forma positiva para a educação, sendo que os professores utilizavam para mandar aulas online, tirar dúvidas sobre diversos assuntos servindo como complemento da aula, chegaram à conclusão que:

Levando em consideração que a escola não possuía telefone, o diálogo pela Internet se tornou o único meio de comunicação fora os encontros presenciais. Por falta de transporte escolar, diversas vezes as aulas foram canceladas. Pela rede os professores avisavam sobre a logística e empecilhos que alterassem as combinações. (OLIVEIRA; HARRES, 2017, p. 26).

Em condições colaborativas devem ser impostas e seguidas a risca, pois não adianta utilizar os recursos sem finalidades específicas e planejamento, somente para constar de que está a incluir as tecnologias na sala de aula, depende de um conjunto de ações e pessoas que colaborem com a proposta imposta em busca sempre de um objetivo específico e ter assim um plano de ação concreto, unidos através de formação de cidadãos conscientes e críticos, pois o contexto educativo em que encontramos em nosso Brasil ainda é lamentável comparado aos países vizinhos, pois temos regiões onde crianças sofrem para conseguir chegar até a escola para ter uma formação, tem se muitos avanços para acontecer, mas os sujeitos envolvidos neste processo devem ir à luta para que se consiga uma educação com melhor qualidade e melhores condições para ensinar e para aprendizado. 
Como conseguir capacitar os professores para a utilização do uso das tecnologias na sala de aula? Pergunta complexa de ser respondida. Se os educadores não tiverem incentivo da direção não haverá vontade de levarem para sala de aula a fonte tecnológica. Por outro lado, se a direção auxiliar os professores com cursos, e capacitações para usarem está fonte os professores terão uma âncora, não é fácil trabalhar algo novo sem ter incentivo, professor deve se manter atualizado se for ao contrário os alunos passaram a sentir a falta desta ferramenta.

A distribuição de Tablets nas escolas não quer dizer que estão a investir em tecnologia para os professores, se não ocorrer de alguma forma capacitação para ajudar os professores a entenderem está ferramenta não terá maior importância, mas os mesmos devem estar preparados para uma nova visão, estar aberto a um novo mundo.

Segundo Ramos (2012, p. 7) "os professores, neste contexto de mudança, precisam saber orientar seus alunos sobre onde e como colher informações, como tratá-las e como utilizá-las, ensiná-los a pesquisarem”. O primeiro passo para o êxito é a instrução, se o mediador souber interferir e auxiliar na pesquisa, busca pelas informações será um grande passo para transformação de informação para conhecimento.

Já dizia Freire (1996, p. 22), “como professor crítico, sou um "aventureiro” responsável, predisposto à mudança, à aceitação do diferente. Nada do que experimentei em minha atividade docente deve necessariamente repetir-se." Portanto, não é porque as crianças são outras que deve se repetir planos por anos e anos, os educadores precisam estar sempre em inovação, aprimorar os novos conhecimentos. As tecnologias servem para auxiliar às inovações solicitadas, sempre buscar o melhor ao conteúdo que é preciso ensinar, de nada adianta o ensino 'bancário’, onde as informações são depositadas e que logo após serão esquecidas e nem sequer serão utilizadas.

O professor deve conhecer o que as novas tecnologias têm a oferecer e agregar a si mesmo, e para seus educandos. De qual forma possibilita um melhor aprendizado e conhecimento. Deve-se ajudar seus educandos a enfrentarem suas dificuldades e anseios, com a ajuda da tecnologia e das ferramentas nela depositadas. A utilização da tecnologia está 
cada vez mais inserida no âmbito da sociedade em geral, a exigência do mundo atual acarreta em englobar as informações em questões de segundos.

Diante disto, acredita-se que as TCI podem trazer benefícios significativos para a educação, seja ela à distância ou presencial, porém, é fundamental que os professores que vão fazer uso destas tecnologias tenham capacidade de reconhecer tanto as vantagens, as limitações e os cuidados que devem ser tomados, como também as implicações do uso destas tecnologias, para a educação em particular e para a sociedade como um todo, para que esses instrumentos possibilitem uma melhora efetiva da qualidade das aulas ministradas. (DANTAS, 2005, p. 15).

Quando propomos o assunto contextos educativos nos vem à tona o conceito que envolve todo o processo, a formação, a formação do ser, a formação de pais, adultos conscientes, consumidores, formação de personalidade, segundo Vaillant e Marcelo (2012, p. 28) "Outro conceito chave é o de ação formativa, atividade formativa ou ações de formação". Ensina-se os alunos para ensinar, desde os princípios são moldados com ensinamentos que formam ações as quais levarão em conta as diversas situações de suas vidas.

Toda fase inicial é complexa, qualquer começo traz consigo as incertezas, o medo, 'aquele frio na barriga', mas com a criatividade de educador se supera tudo, todos sabem que a tarefa é difícil, mas jamais desistem e buscam-se meios para facilitá-la, pois já dizia Dantas (2005, p. 20) "a formação inicial pode ajudar o futuro professor a produzir e legitimar os saberes que irá utilizar na sua profissão, fato que certamente diminuiria o choque com a realidade, característico das primeiras experiências do professor no seu ambiente de trabalho".

Dantas (2005, p. 24) “conclui que, porém, pode-se perceber que as escolas e os professores não se encontram capacitados para utilizar adequadamente estas tecnologias, entre outros motivos, devido à deficiente formação inicial que lhes é fornecida pelos cursos universitários.” Portanto é de grande valia a formação continuada e o acompanhamento do aprendizado do educador nesta nova fase difícil que está a enfrentar, é necessário apoio para que consiga resultados significativos. 
No cenário atual em que a educação está, enfrenta-se dificuldade de inserir o "novo" em sala de aula, as barreiras são grandes, os obstáculos também. Professor deve ser persistente sem ter medo de novidades, o novo sempre dá medo até conhecer realmente os seus benefícios e o que deve ajudar em sala de aula para deixar suas aulas mais desejantes e aprendentes.

Estuda-se por necessidade das coisas, pois precisa de formação, de profissão, a maioria busca ser o melhor na sua profissão, na sua área quer ser o exemplo, mas para isso é preciso inovação, a busca pelo novo, ter o senso crítico e buscar cada vez mais adquirir conhecimentos usando as novas tecnologias da informação e comunicação, pois já citava Mercado (1999, p. 27):

As novas tecnologias criam novas chances de reformular as relações entre alunos e professores e de rever a relação da escola com o meio social, ao diversificar os espaços de construção do conhecimento, ao revolucionar os processos e metodologias de aprendizagem, permitindo à escola um novo diálogo com os indivíduos e com o mundo.

Uma forma de incrementar o ensino de maneira prazerosa e que cativa os alunos pois utilizara o que tem de novo aos quais os mesmos gostam e querem usar no seu cotidiano diário. As faculdades deveriam começar a preparar os profissionais para que enfrentem este momento com o uso destas novas tecnologias que estão cada vez mais avançadas, pois Stahl (1997, p. 312) considera que “a inclusão de uma disciplina específica nos cursos de formação de professores parece ser o caminho para que todos os futuros professores cheguem às escolas dominando certas habilidades”.

É possível buscar auxílio dos alunos, suporte deste que muitas vezes fará com que aprenda como fazer um vídeo ou montar uma tabela no Excel, por exemplo, coisas que parecem simples, mas que exige a prática, algumas pessoas tendo acesso buscam os recursos e conseguem auxiliar as demais nesse momento. Paiva já citava (2013, p. 10) "pelo que vimos até agora, a formação do professor para uso da tecnologia, raramente acontece de forma sistematizada. Isso não é diferente no Brasil, onde a formação tecnológica fica, geralmente, restrita a iniciativas individuais". 
Deve-se aliar a teoria e a prática, a alternativa ocorre com a conjugação entre conhecimento e vivência quanto mais se exercita alguma tarefa mais fácil será lembrada, de nada adianta ter cursos sobre como utilizar e não explorar os recursos para aperfeiçoar e descobrir coisas novas, a pratica 'leva a perfeição’, quanto mais for explorado, mais aprendizado será adquirido ao decorrer do tempo e estes poderão ser utilizados nas aulas práticas com os alunos, pois só pensa quem é estimulado a pensar, a partir do momento que você lê um livro, por exemplo, automaticamente está sendo estimulado a escrever e a ler novos livros.

A tecnologia de forma alguma se apresenta como a solução de todos os problemas da educação, muito pelo contrário chega para auxiliar nesta etapa de inovação, interdisciplinaridade e comprometimento com a qualidade de ensino, traz ferramentas que beneficiam na facilidade e compreensão de diversos conteúdos que serão explanados pelos professores.

\section{Considerações finais}

O estudo constituiu-se a partir da reflexão em vários autores a respeito do uso das tecnologias, como base para a formação humana nos processos educativos. Neste sentido, constatou-se a necessidade de criar nos espaços educativos uma consciência de preocupação e sensibilidade no uso das tecnologias naquilo que consideremos ser uma educação humanizadora. Desse modo, os espaços educativos construídos pelas equipes diretivas (direção, coordenação pedagógica, professores, estudantes e comunidade) precisam buscar cada vez mais participarem de cursos de formação continuada que deem incentivo e possibilitem criar estratégias didáticas como novas entradas para construção das próprias práticas pedagógicas, e sobretudo, a inclusão e o reconhecimento do outro, ou seja, no dinamismo dos processos humanizatórios de reconhecimentos do ser humano nos espaços educativos. 


\section{HUMANIZING EDUCATION AND THE USE OF TECHNOLOGIES}

ABSTRACT: The aim of this study is to reflect on the construction of didactic practices with the use of TICS in the process of teaching learning in a perspective of humanizing education. It is an investigation, whose methodological outline, constitutes a bibliographical study. Based on the literature, it investigates the need to create public policies that ensure spaces of continuing education for educators and managers of schools, without doubt the result of this reflection is the viable and possible construction of humanizing educational processes and teaching practices that include the use of technologies in training human beings critical and sensitized with the different ways of living.

KEYWORDS: Education; Humanization; Training; Technology.

\section{EDUCACIÓN HUMANIZADORA Y EL USO DE LAS TECNOLOGÍAS}

RESUMEN: Se objetiva con ese estudio reflexionar sobre la construcción de prácticas didácticas con el uso de las TICS en el proceso de enseñanza aprendizaje en una perspectiva de educación humanizadora. Se trata de una investigación, cuyo delineamiento metodológico, se constituye en un estudio bibliográfico. Se concluyó con base en la literatura investiga la necesidad de crear políticas públicas que aseguren espacios de formación continuada a los educadores y gestores de las escuelas, sin duda el resultado de esa reflexión es la construcción viable y posible de procesos educativos humanizantes y de prácticas docentes que incluyan el " el uso de tecnologías en la formación de seres humanos críticos y sensibilizados con los diferentes modos de vivir.

PALABRAS-CLAVE: Educación; formación continua; Humanización, Tecnología.

\section{REFERÊNCIAS}

ALTOÉ, F. Computador na educação e os desafios educacionais. Disponível em: https://goo.gl/KunZUw, 2009. Consultado em 13 de maio de 2019.

ALVES, R. A alegria de ensinar, 1994. Disponível em: https://goo.gl/VmU0f5. Consultado em: 24 de maio de 2017.

ARAÚJO, Guilherme Rodrigues, BARROS, Camila Martins. Novas Tecnologias: Escola Pública versus Escola Particular, 2012. Disponível em: https://goo.gl/dKbFhV. Consultado em: 26 de agosto de 2017.

ASSMANN, Hugo. Reencantar a educação: rumo à sociedade aprendente. Petrópolis: Vozes, 2012.

DANTAS, Aleksandre Saraiva. A formação inicial do professor para o uso das tecnologias de comunicação e informação. 2002. Disponível em: https://goo.gl/oMQ6U9. Consultado em: 25 de setembro de 2017. 
FREIRE, Paulo. Pedagogia do oprimido, 1987. Disponível em: https://goo.gl/K5ZF6G. Consultado em: 24 de maio de 2017.

FREIRE, Paulo. Pedagogia da Autonomia- Saberes necessário à prática educativa, 1996. Disponível em: https://goo.gl/LYyXKG. Consultado em 24 de maio de 2017.

LIBÂNEO, Jose Carlos. Organização e gestão da escola teoria e prática, 2001. Disponível em: https://goo.gl/qG9mmk. Consultado em: 18 de maio de 2017.

LIBÂNEO, Jose Carlos. Adeus professor, adeus professora: novas exigências educacionais e profissão docente. São Paulo: Cortez, 2011.

MACIEL. Formação humana: reflexões sobre uso das tecnologias para ensinar e aprender, 2009. Disponível em: https://goo.gl/RfL9yl. Consultado em 01 de maio de 2017.

MATURANA, Humberto. Emoções e linguagem na educação e na política, 2002. Disponível em: https://goo.gl/y06eNN. Consultado em 18 de maio de 2017.

MERCADO, Luís Paulo Leopoldo. Formação docente e novas tecnologias, 1998. Disponível em: https://goo.gl/AuvxWR. Consultado em 03 de novembro de 2017.

MERCADO, Luís Paulo Leopoldo. Formação continuada de professores e novas tecnologias. Maceió: EDUFAL, 1999.

MORIN, Edgar. Os sete saberes necessários à educação do futuro. São Paulo: Cortez; Brasília: UNESCO, 2000.

MORIN, Edgar. (2000): Os sete saberes necessários à educação do futuro. Tradução de Catarina Eleonora F. da Silva e Jeanne Sawaya; revisão técnica de Edgard de Assis Carvalho, São Paulo: Cortez; Brasília: UNESCO, 2000. Disponível em: https://goo.gl/KDwg0b. Consultado em 21 de maio de 2017.

MORIN, Edgar. A cabeça bem-feita: repensar a reforma, reformar o pensamento. Tradução de Eloá Jacobina, Rio de Janeiro, Bertrand Brasil, 2003. Disponível em: https://goo.gl /Ix9fod. Consultado em 21 de maio de 2017.

NOGUEIRA, Nilbo Ribeiro. Práticas pedagógicas e uso da tecnologia na escola. São Paulo: Érica, 2014.

OLIVEIRA, Letícia Paranhos Menna de, HARRES, João Batista Siqueira. O uso do facebook como ferramenta para a construção coletiva de uma proposta pedagógica, 2017. Disponível em: https://goo.gl/BNg2rR. Consultado em 18 de setembro de 2017.

PAIVA, V. L. M . O. A formação do professor para uso da tecnologia. In: SILVA, K. A, DANIEL, F. G., KANEKO-MARQUES, S. M. e SALOMÃO, A. C. B. (Orgs). A formação de professores de línguas: novos olhares. Volume 2, Campinas: Pontes Editores, 2013.

PERRENOUD, Philippe. 10 novas competências para ensinar. Trad. Patrícia Chittoni Ramos, Porto Alegre: Artes Médicas, 2000. 
RAMOS, Márcio Roberto Vieira. O uso de tecnologias em sala de aula, 2012. Disponível em: https://goo.gl/OoijIk. Consultado em: 21 de agosto de 2017.

RÊEG, Eduardo Ernesto do, SERAFIM, Maria Lúcia. A utilização dos aplicativos google maps e google earth no ensino de geografia: múltiplas possibilidades, 2014. Disponível em:

https://goo.gl/Qo6Dvu. Consultado em 24 de maio de 2017.

SAVIANI, Dermeval. (1999): Escola e democracia, 1999. Disponível em:

https://goo.gl/ZpsnR8. Consultado em 18 de maio de 2017.

SEEGGER; CANES e GARCIA. Estratégias tecnológicas na prática pedagógica, 2012. Disponível em: https://goo.gl/RcLHme. Consultado em 10 de abril de 2017.

STRIEDER, Roque e ZIMMERMANN, Rose Laura G. A educação ainda em processo de construção. Florianópolis: DIOESC, 2012.

STRIEDER, Roque. Educar para a iniciativa e a solidariedade. Ijuí: UNIJUÍ, 2000.

STRIEDER, Roque. Educação e Humanização: por uma vivência criativa. Florianópolis: Habitus, 2002.

Recebido em: 30/08/2019.

Aprovado em: 30/10/2019. 